\title{
Fetal Cardiovascular Effects of Nifedipine in Rats
}

\author{
KAZUO MOMMA AND ATSUYOSHI TAKAO \\ Department of Pediatric Cardiology, The Heart Institute of Japan, Tokyo Women's Medical College, \\ Tokyo, Japan
}

\begin{abstract}
In this study we clarify the fetal cardiovascular effects of nifedipine. Nifedipine was administered to near-term rats and cardiovascular morphology of the fetus was studied with a rapid whole-body freezing technique. Fetal cardiac failure was estimated by accumulation of pericardial effusion and ventricular dilatation. Dose-response study at $8 \mathrm{~h}$ after administration revealed that slight ventricular dilatation occurred with $0.1 \mathrm{mg} / \mathrm{kg}$ of nifedipine, and remarkable ventricular dilatation and pericardial fluid accumulation were noted with $10 \mathrm{mg} / \mathrm{kg}$ nifedipine. Timecourse study with one dose of $10 \mathrm{mg} / \mathrm{kg}$ nifedipine revealed early ventricular dilatation at $1 \mathrm{~h}$, peak ventricular dilatation and fluid accumulation at $8 \mathrm{~h}$, and slight effects at 24 $h$. In conclusion, the cardiodepressive effect of nifedipine in the fetal rat was mild with the therapeutic dose, and its effects increased dose dependently. (Pediatr Res 26:442447, 1989)
\end{abstract}

Nifedipine may be used to treat hypertension $(1,2)$ or premature labor (3-5) of pregnant women. However, it has been shown in in vitro study that the cardiodepressive effects of nifedipine and other calcium antagonists are more prominent in premature than adult hearts $(6,7)$. Very little is known about cardiovasular effects of these calcium antagonists in the fetus because of difficulty in studying the fetal heart. The purpose of our study was to clarify the cardiovascular effects of nifedipine in the fetal rat. Previously established methods (8) were used to

Received February 11, 1989; accepted June 8, 1989.

Supported partly by grants-in-aids from the Ministry of Science, Education and Culture of Japan, The Ministry of Health and Welfare of Japan, and Japan Research Promotion Society for Cardiovascular Diseases.

Correspondence to Dr. K. Momma, The Heart Institute of Japan, Tokyo Women's Medical College, Kawadacho 8-1, Shinjukuku, Tokyo 162, Japan. study quantitatively the cardiovascular effects of maternally administered drugs to the fetal rat.

\section{MATERIALS AND METHODS}

Virgin Wistar rats (pregnancy period $21.5 \mathrm{~d}$ ) were mated overnight and the presence of sperm on vaginal smears dated the $0 \mathrm{~d}$ of pregnancy. These rats were fed commercial solid food and water. Drugs were administered through an orogastric tube in a suspension of $2 \mathrm{~mL}$ water containing $5 \%$ arabic gum on the $21 \mathrm{st}$ $\mathrm{d}$ of pregnancy.

Two to six pregnant rats were used in each experimental group as shown in Table 1. Pregnant animals were sacrificed by cervical dislocation, and fetuses were delivered quickly by cesarean section, and fixed immediately by the whole-body freezing technique $(9-11)$ using acetone cooled to $-80^{\circ} \mathrm{C}$ by dry ice. For morphologic study of the heart, the thorax of the frozen rat was trimmed and sectioned on a freezing microtome (Freezing Microtome, Komatsu Solidate Co., Tokyo, Japan) in the short axis plane of the heart as described previously (8). Sections $0.5-\mathrm{mm}$ thick were cut serially from the cardiac apex to the cranial end of atria, and the surfaces of these cross-sections were photographed using a binocular stereoscopic microscope (Wild M 400 Photo-Macroscope, Wild Heerbrugg Ltd., Heerbrugg, Switzerland) and color film (Fujicolor Super HR 100, Fuji Film Co., Tokyo, Japan). A magnification of $9.5 \times$ was used. In the fetal heart, 15-16 sections were recorded. Numbered section paper was also photographed and used for scale. The photographs were printed in color on paper, $116 \times 81 \mathrm{~mm}$ in size. Morphology and volumetric study of the cardiac chambers in situ were studied on these prints as described in the previous paper (8). Briefly, volumes and masses of two ventricles and volumes of two atria were measured by adding the areas of each on these photographs. The accuracy of this method was tested and reported previously (8). Pericardial effusion was assessed by measuring the thickness of the pericardial space at 10 points around the ventricles at the level of the left ventricular papillary muscles.

Table 1. Numbers of treated pregnant rats and numbers of studied fetuses in each experiment

\begin{tabular}{|c|c|c|c|}
\hline Experiment & Drug and dose $(\mathrm{mg} / \mathrm{kg})$ & $\begin{array}{c}\text { Timing: } \\
\text { h after } \\
\text { medication }\end{array}$ & $\begin{array}{l}\text { No. of pregnant rats } \\
\text { (no. of fetuses) }\end{array}$ \\
\hline \multirow[t]{5}{*}{ Dose-effects of nifedipine } & None (21st day) & & $4(19)$ \\
\hline & Nifedipine 0.01 & 8 & $2(10)$ \\
\hline & Nifedipine 0.1 & 8 & $2(9)$ \\
\hline & Nifedipine 1 & 8 & $3(10)$ \\
\hline & Nifedipine 10 & 8 & $3(14)$ \\
\hline \multirow[t]{5}{*}{ Time-course of nifedipine effects } & Nifedipine 10 & 1 & $2(14)$ \\
\hline & Nifedipine 10 & 4 & $2(10)$ \\
\hline & Nifedipine 10 & 8 & $3(14)$ \\
\hline & Nifedipine 10 & 24 & $2(14)$ \\
\hline & None (22nd d) & & $3(22)$ \\
\hline
\end{tabular}


Dose-effects of nifedipine was studied as follows. Because of photosensitivity of nifedipine, exposure to strong light was carefully avoided. Solid-solution of nifedipine (Sepamit Fine Granule, Kanebo Pharmaceutical Co., Tokyo, Japan) was used after dilution with lactose. The absorption of Sepamit Fine Granule is the same as that of soft gelatin capsule containing dissolved nifedipine (Adalat, Bayer, Toyko, Japan) following oral administration to beagle dogs and healthy volunteers (12). Doses of $0.01,0.1,1$, or $10 \mathrm{mg} / \mathrm{kg}$ of nifedipine were administered to the pregnant rat, and the fetus was studied $8 \mathrm{~h}$ later. This time was selected because cardiac failure was most prominent.

Time-course of nifedipine effect was studied at 1, 4, 8, and 24 $\mathrm{h}$ after administration of $10 \mathrm{mg} / \mathrm{kg}$ nifedipine. A dose of $10 \mathrm{mg} /$ $\mathrm{kg}$ was used because this dose caused clear signs of congestive failure in the fetus.

The results are expressed as mean \pm SEM. Two-way analysis of variance and Duncan's multiple range $t$ test were used for statistical analysis to determine the significance of difference of

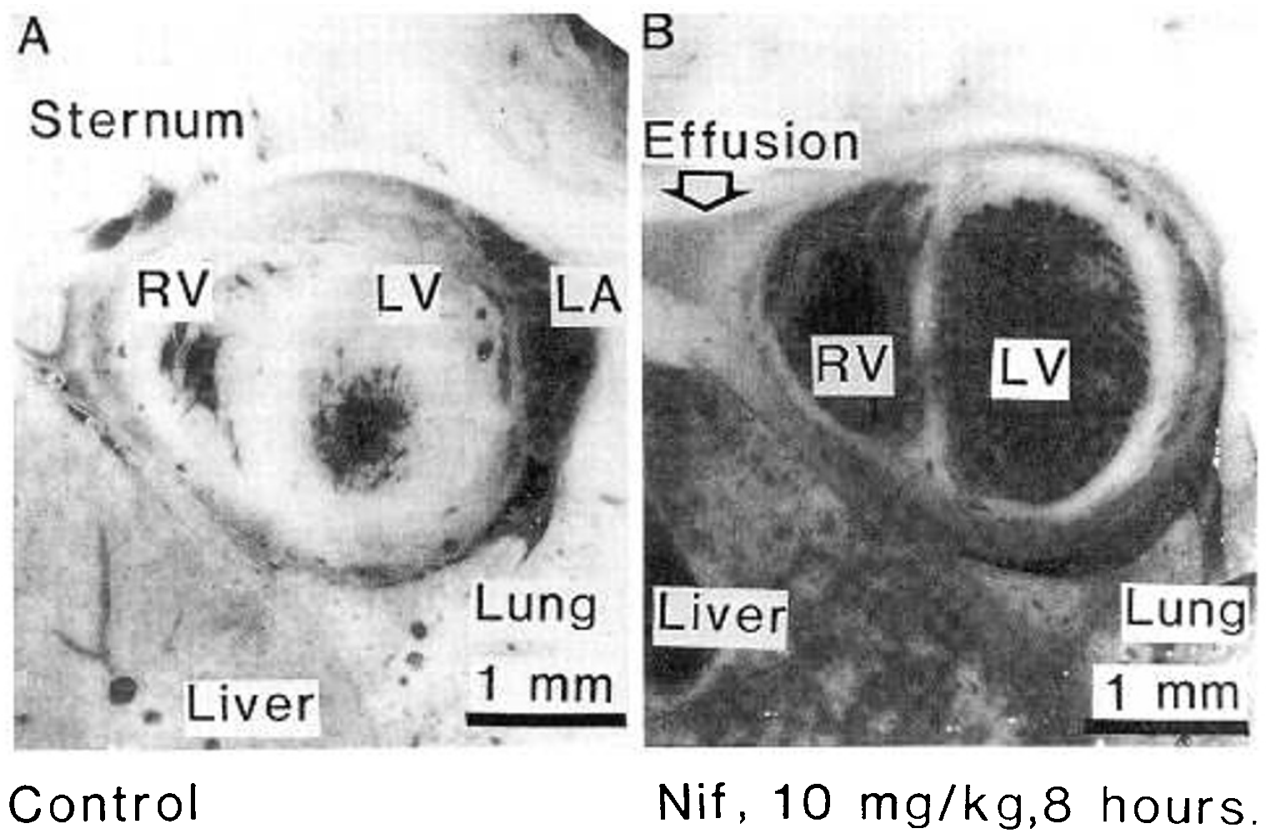

Fig. 1. Fetal cardiac failure by nifedipine. Ventricular cross-sections of fetal rats in the cardiac short axis. The fetus was delivered by cesarean section and was frozen immediately. The ventricles of a control fetus shows small cavities and thick walls $(A)$. Only a small amount of pericardial fluid is noticed. In contrast, the fetus of the mother treated with nifedipine $10 \mathrm{mg} / \mathrm{kg} 8 \mathrm{~h}$ before shows dilated right and left ventricles and increased pericardial, pleural, and peritoneal effusions $(B)$. $L A$, left atrium; $L V$, left ventricle; $R V$, right ventricle.

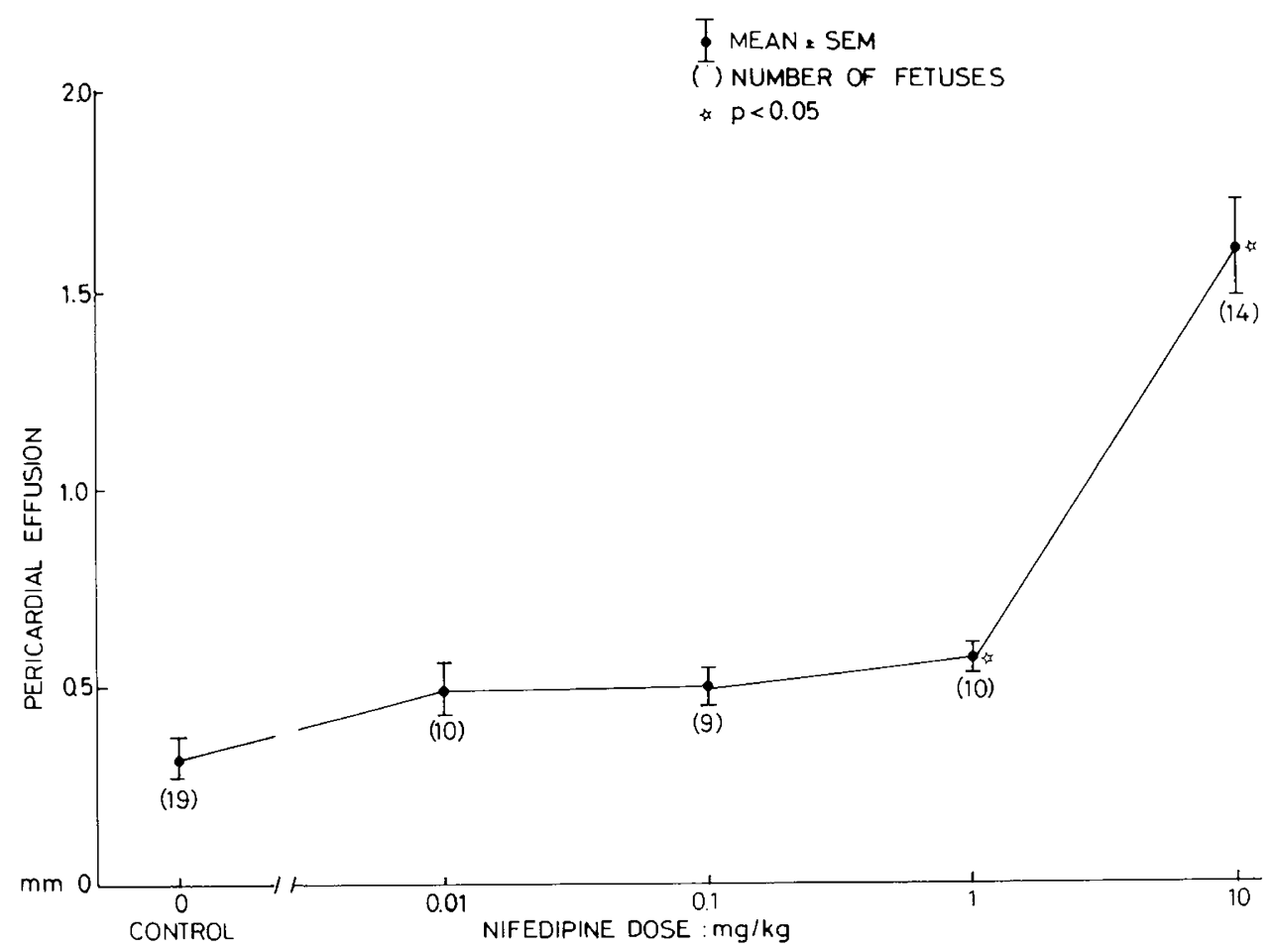

Fig. 2. Fetal pericardial effusions at $8 \mathrm{~h}$ after administration of various doses of nifedipine to the pregnant rat. The ordinate shows the thickness of the pericardial space measured at 10 points around the ventricles. 
the mean value (13). Five percent was accepted as the level of significance

\section{RESULTS}

Signs of cardiac failure. Massive accumulation of pericardial, pleural and peritoneal fluid and remarkable dilatation of ventricles were observed in fetal rats $8 \mathrm{~h}$ after administration of 10 $\mathrm{mg} / \mathrm{kg}$ of nifedipine to the mother rat (Fig. 1). Increase in pericardial effusion was always associated with increase in pleural and peritoneal effusions. The increased effusions were always associated with dilatation of the ventricles. In contrast, the sizes of the atria, the ascending and descending aorta, the ductus arteriosus, the main and the right and left pulmonary arteries, the superior and inferior venae cavae were not different from controls.

Dose-effects study. Accumulation of pericardial effusion at $8 \mathrm{~h}$

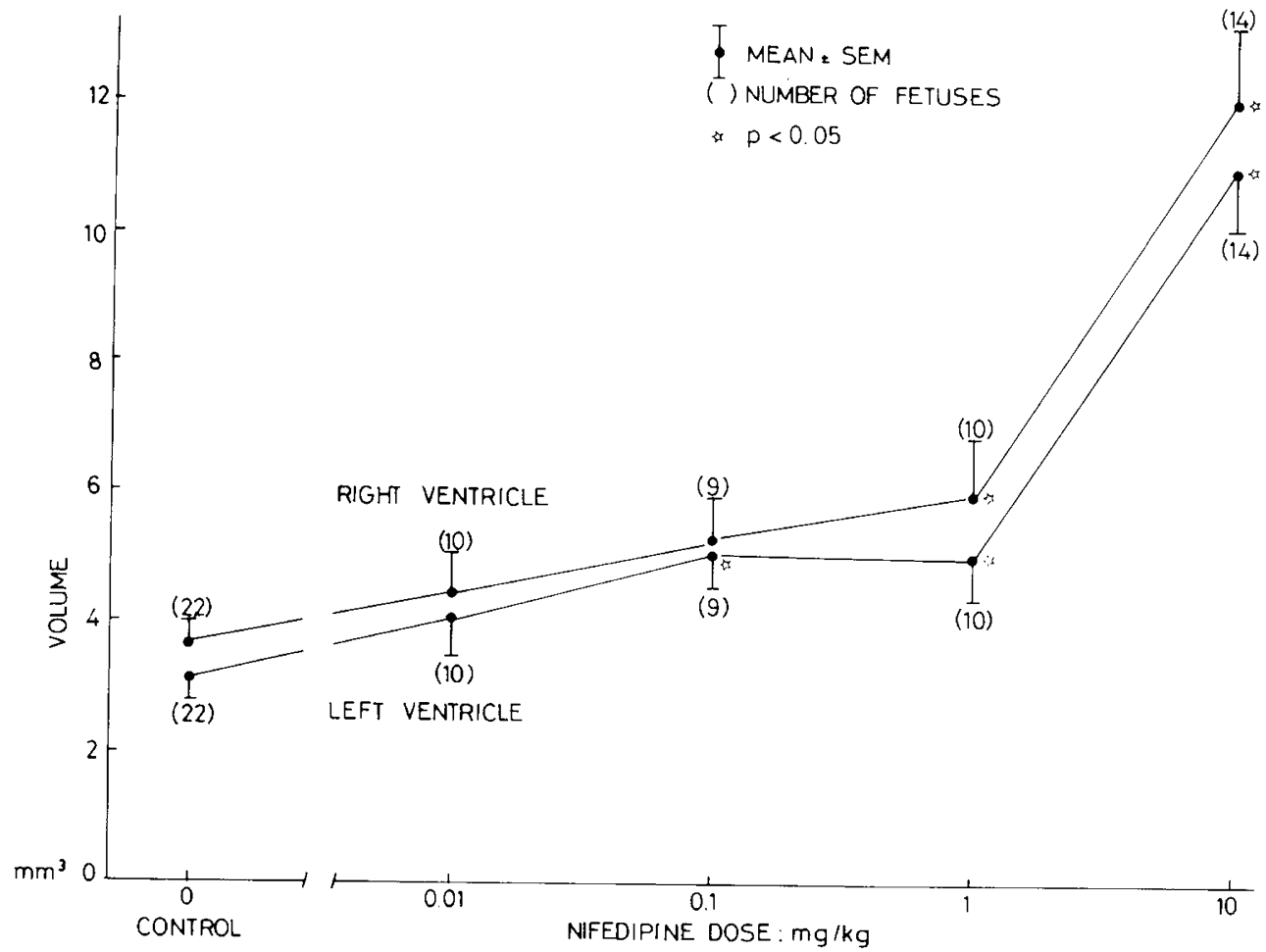

Fig. 3. Fetal right and left ventricular volumes at $8 \mathrm{~h}$ after administration of various doses of nifedipine to the pregnant rat.

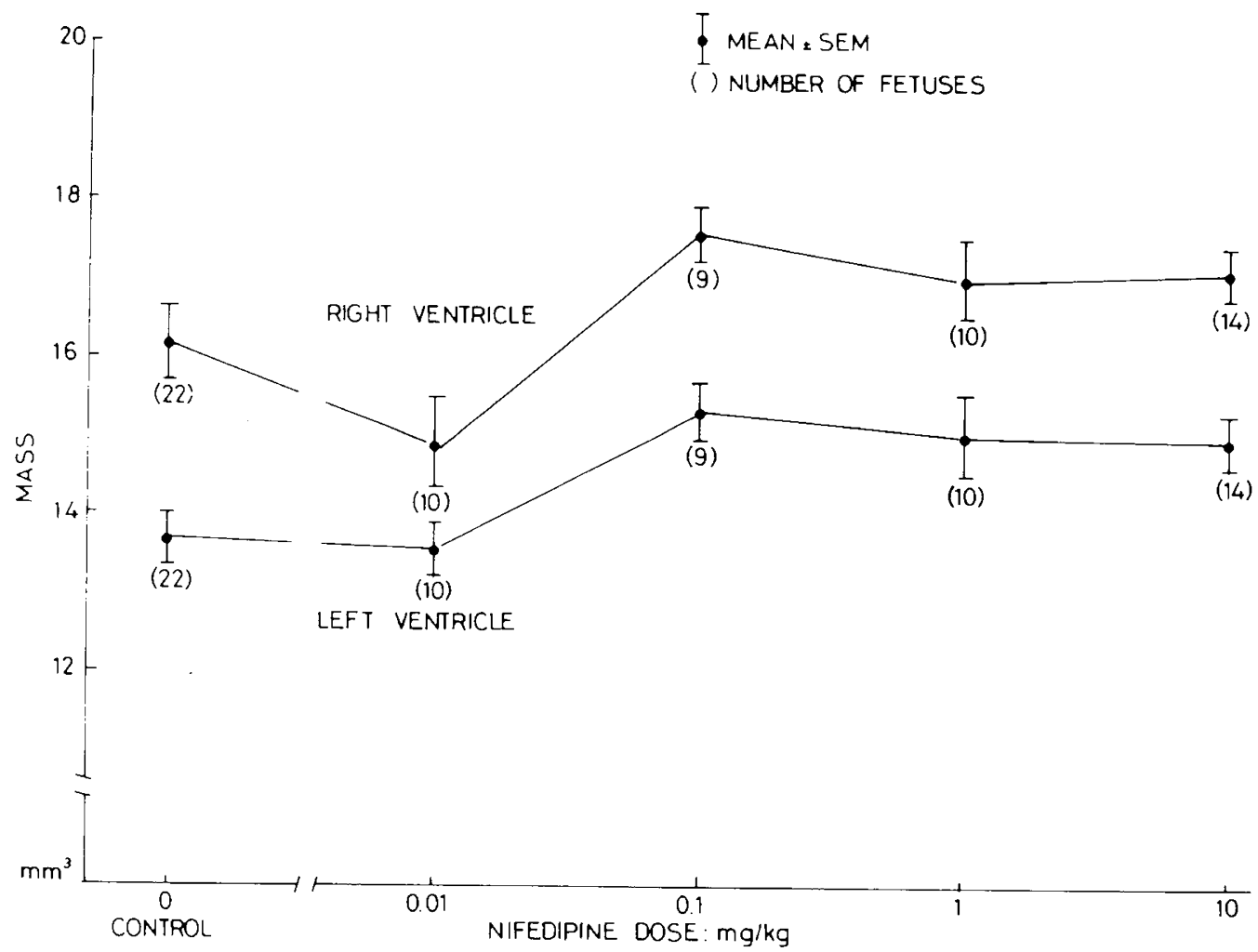

Fig. 4. Fetal right and left ventricular masses at $8 \mathrm{~h}$ after administration of various doses of nifedipine to the pregnant rat. 
after administration of nifedipine was dose-dependent (Fig. 2). Mild increase of pericardial effusion was noticed with 0.1 or 1 $\mathrm{mg} / \mathrm{kg}$ nifedipine, but it increased to $500 \%$ of control with 10 $\mathrm{mg} / \mathrm{kg}$ nifedipine. Fetal ventricular dilatation was also dose dependent (Fig. 3 ); with $0.1 \mathrm{mg} / \mathrm{kg}$ nifedipine, ventricular volumes increased mildly and significantly and with $10 \mathrm{mg} / \mathrm{kg}$ nifedipine, ventricular volume increased remarkably and reached more than $300 \%$ of controls. Fetal right and left ventricular masses showed slight increase with $0.1,1$, and $10 \mathrm{mg} / \mathrm{kg}$ nifedipine, but this increase was not significant (Fig. 4). Fetal right atrial volume increased slightly and insignificantly and left atrial volume did not increase (Fig. 5).

Time course of fetal cardiovascular effects of nifedipine $(10$ $\mathrm{mg} / \mathrm{kg}$ ). Time course for the accumulation of pericardial effusion is shown in Figure 6 . After single large dose $(10 \mathrm{mg} / \mathrm{kg})$ of nifedipine, pericardial effusion increased progressively, and

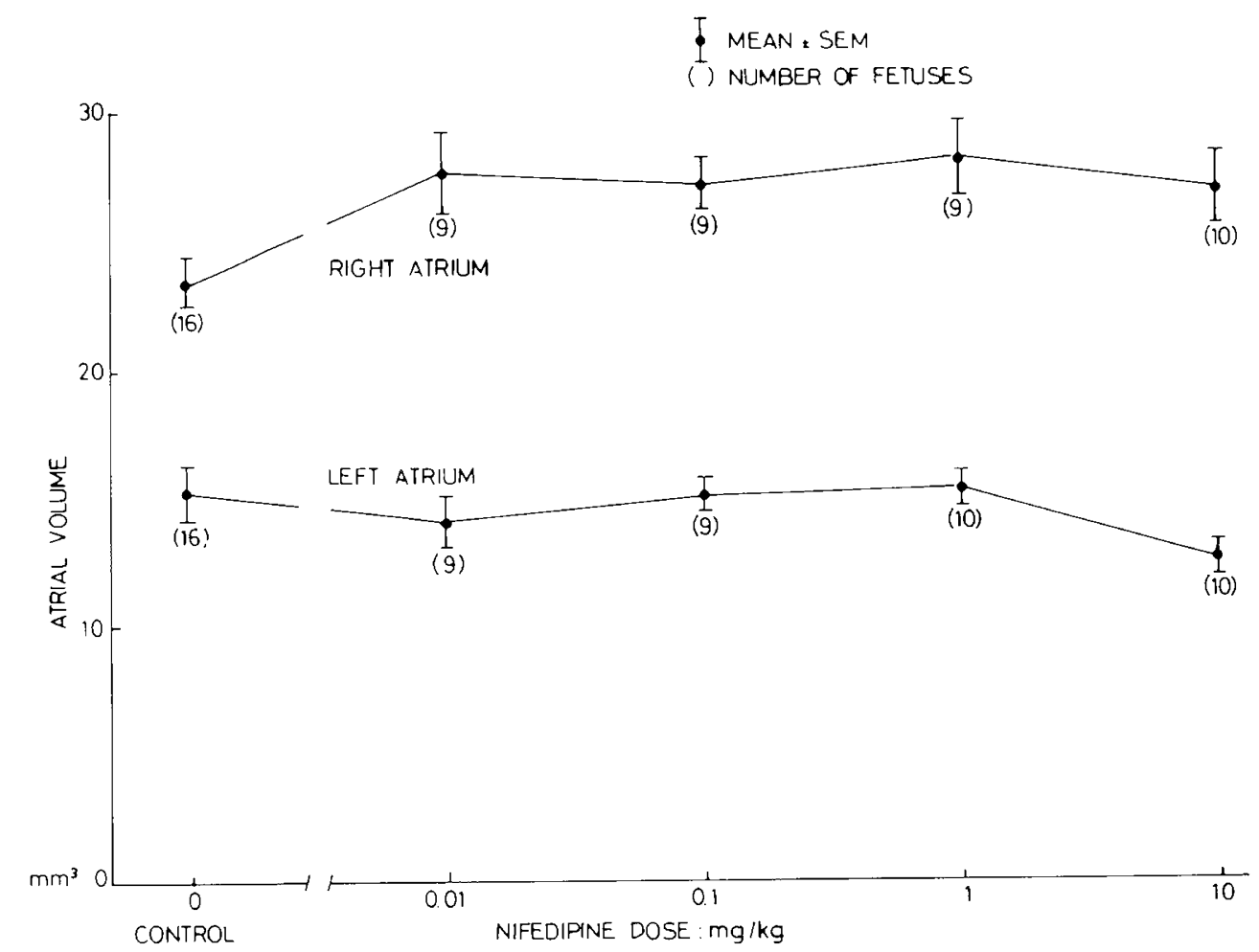

Fig. 5. Fetal right and left atrial volumes at $8 \mathrm{~h}$ after administration of various doses of nifedipine to the pregnant rat.

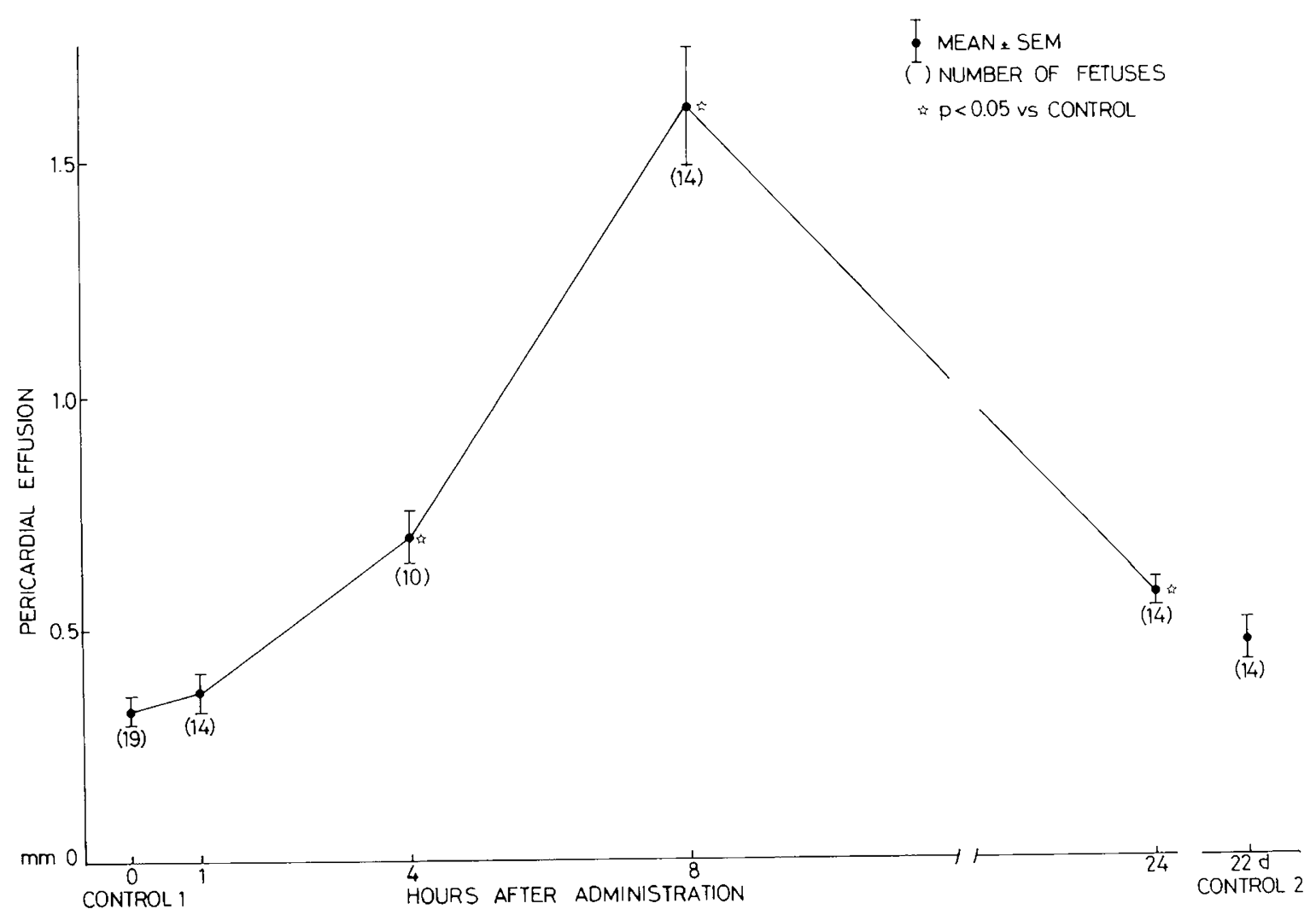

Fig. 6. The time course of fetal pericardial effusion after administration of $10 \mathrm{mg} / \mathrm{kg}$ nifedipine to the pregnant rat ( $10 \mathrm{mg} / \mathrm{kg}$ ). 
reached maximum at $9 \mathrm{~h}$. Even at $24 \mathrm{~h}$, the effusion was slightly larger than the control. Time course for the increase in ventricular volumes is shown in Figure 7. The onset of ventricular dilatation was rapid and clearly noticed at $1 \mathrm{~h}$. Ventricular dilatation was maximum at $8 \mathrm{~h}$, persisting only slightly at $24 \mathrm{~h}$.
No significant change was noticed in right and left ventricular mass from 1 through $24 \mathrm{~h}$. The time course for right and left atrial volumes is shown in Figure 8 . Right atrial volume was significantly increased at $\mathrm{l}$ and $4 \mathrm{~h}$. The left atrial volume did not change.
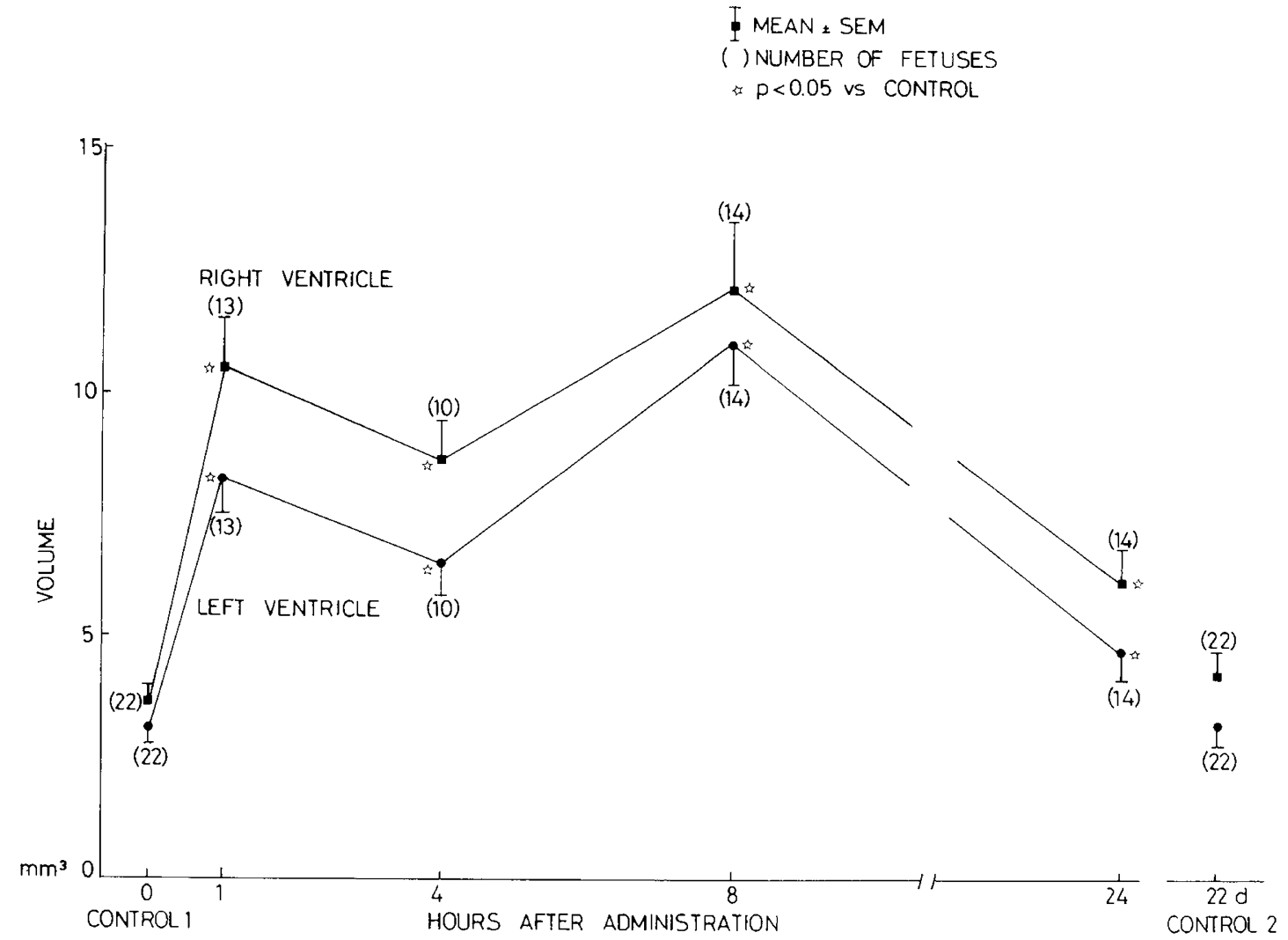

Fig. 7. The time course of fetal right and left ventricular volumes after administration of $10 \mathrm{mg} / \mathrm{kg}$ nifedipine to the pregnant rat ( $10 \mathrm{mg} / \mathrm{kg}$ ).

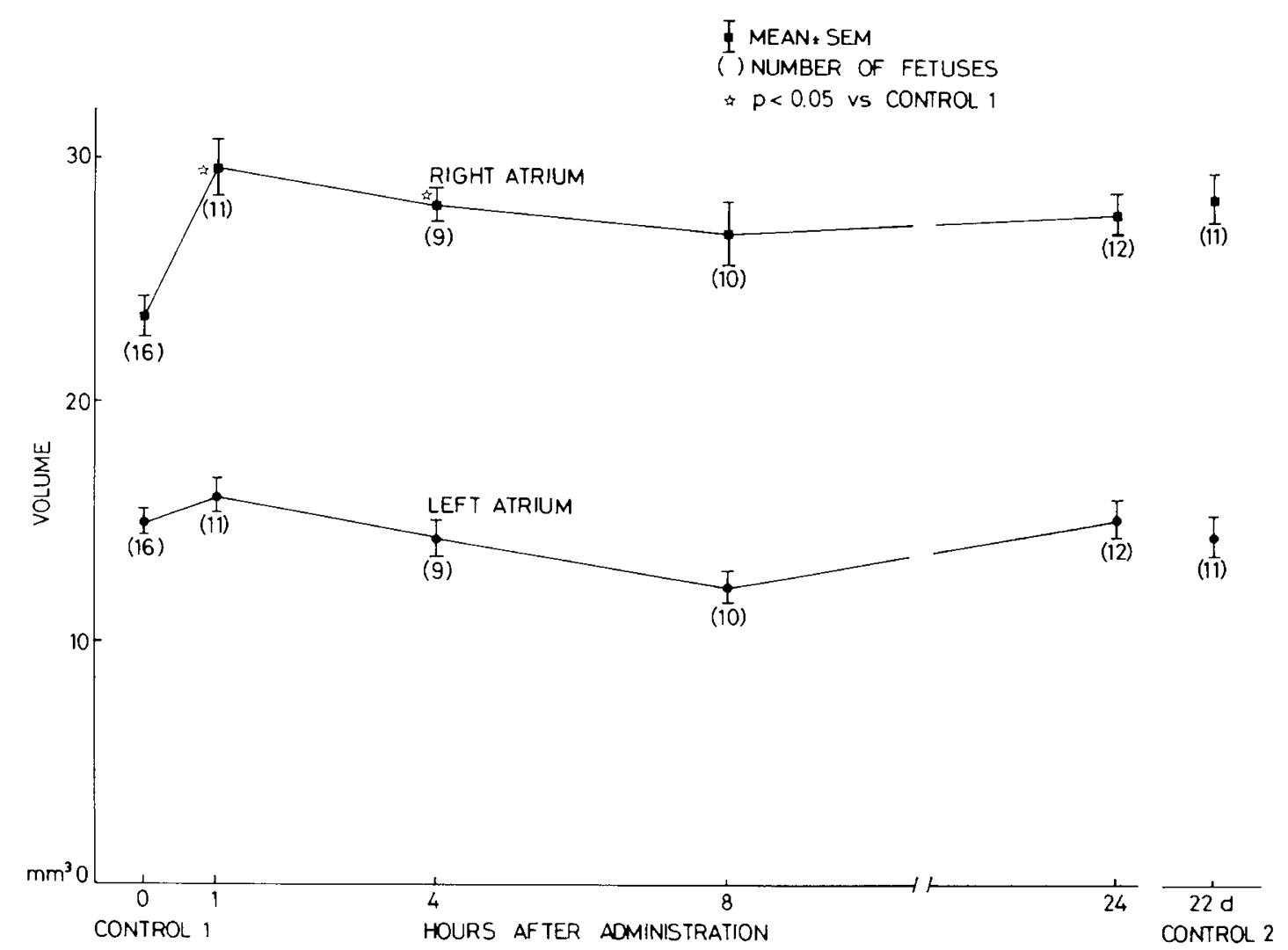

Fig. 8. The time course of fetal right and left atrial volumes after administration of $10 \mathrm{mg} / \mathrm{kg}$ nifedipine to the pregnant rat $(10 \mathrm{mg} / \mathrm{kg})$. 


\section{DISCUSSION}

Nifedipine, diltiazem, and verapamil are three major calcium antagonists (14). Nifedipine belongs to dihydropyridine-group, and has more potent vascular effect than the other two (14). However, direct negative inotropic effect of nifedipine in some experiments with isolated hearts is more potent than verapamil and diltiazem (14).

Recent evidence suggests that the premature myocardium is more sensitive to calcium antagonists and the negative inotropic effect of calcium antagonists is more prominent in infants than in adults $(6,7)$. Further basic study has shown that the sarcoplasmic reticulum of newborn animals is poorly developed and the neonatal heart is more dependent on transsarcolemmal calcium influx for excitation-contraction coupling as compared to the adult heart (15).

Pericardial effusion and ventricular dilatation are signs of cardiac failure (16). Mild but definite signs of fetal cardiac failure were noticed with $0.1 \mathrm{mg} / \mathrm{kg}$ of nifedipine $(0.1 \mathrm{mg} / \mathrm{kg})$ in this study. This is not surprising because we are studying fetal hearts whose sarcoplasmic reticulum is less developed and which are more sensitive to negative inotropic effect of calcium antagonists than in the newborn animal. This degree of negative inotropism in the fetal heart is probably not apparent clinically, and compatible with the early report that the fetus and the newborn did well after therapeutic administration of nifedipine (10 to $30 \mathrm{mg}$ ) for the treatment of hypertension (2) or premature labor $(4,5)$ in pregnant women. These therapeutic doses $(10$ to $30 \mathrm{mg})$ correspond approximately to 0.1 to $0.4 \mathrm{mg} / \mathrm{kg}$ of body wt. However, in one report the perinatal mortality was high after administration of nifedipine for treatment of hypertension in pregnant women (1).

Another explanation for the observed increase in ventricular volume are changes in placental function (17) and an increase in fetal intravascular volume after administration of nifedipine to the pregnant rat. This hypothesis remains to be proved. It can also be argued that a calcium channel blocker can change the phase of ventricular contraction at the instance of rapid wholebody freezing. This also remains to be studied.

Only a few studies are available on the cardiovascular effects of nifedipine in the fetus or newborn animals or humans. Coe $e t$ al. (18) studied the circulatory effects of nifedipine in the instrumented conscious newborn lamb. They showed definite cardiodepressive effects after 5 min of intravenous infusion of $50 \mu \mathrm{g} /$ $\mathrm{kg} / \mathrm{min}$ of nifedipine. Transient decrease of the resistance in the umbilical artery was assessed by recording the pulsatile index in the human fetus after administration of nifedipine $(10 \mathrm{mg})$ to the mother (17). Our study shows the cardiodepressive effects of nifedipine in the fetus after administration to the mother, especially its dose dependency and time course. Assuming that there are no major species differences in response to nifedipine, our results indicate that therapeutic doses of nifedipine have a mild but definite cardiodepressive effect on the fetus. Although fetal plasma concentration of nifedipine were not measured in this study, several studies have shown easy transfer of nifedipine from the mother to the fetus (19). The results of our study are compatible with these early results.

\section{CONCLUSION}

Nifedipine has cardiodepressive effects in the fetus after administration to the pregnant rat. These effects are dose dependent and persist more than $24 \mathrm{~h}$ after a single dose. Therapeutic dose have mild but significant effects.

Acknowledgments. Editorial help of Dr. Leonard M. Linde, Professor of Pediatrics (Cardiology), University of Southern California School of Medicine, is highly appreciated.

\section{REFERENCES}

1. Constantine G, Beevers DG, Reynolds AL, Luesley DM 1987 Nifedipine as a second line antihypertensive drug in pregnancy. $\mathrm{Br} J$ Obstet Gynecol 94:1136-1142

2. Walters BNJ, Redman CWG 1984 Treatment of severe pregnancy-associated hypertension with the calcium antagonist nifedipine. Br J Obstet Gynecol 91:330-336

3. Golichowski AM, Hathaway DR, Fineberg N, Peleg D 1985 Tocolytic and hemodynamic effects of nifedipine in the ewe. Am J Obstet Gynecol 151:1134-1140

4. Read MD, Wellby DE 1986 The use of calcium antagonist (nifedipine) to supress preterm labour. Br J Obstet Gynecol 93:933-937

5. Ulmsten U, Anderson KE, Winegerup L 1980 Treatment of premature labor with calcium antagonist nifedipine. Arch Gynecol 229:1-5

6. Boucek RJ Jr, Shelton M, Artman M, Mushlin PS, Starnes VA, Olson RD 1984 Comparative effects of verapamil, nifedipine, and diltiazem on contractile function in the isolated immature and adult rabbit heart. Pediatr Res 18:948-952

7. Seguchi M, Jarmakani JM, George BL, Harding JA 1986 Effects of Ca antagonists on mechanical function in the neonatal heart. Pediatr Res 20:838-842

8. Momma K, Takao A, Ito R, Nishikawa T 1987 In situ morphology of the heart and great vessels in fetal and newborn rats. Pediatr Res 22:573-580

9. Hoernblad PY, Larson KS 1967 Studies on closure of the ductus arteriosus. I. Whole-body freezing as improvement of fixation procedures. Cardiologia 51:231-241

10. Momma K, Uemura S, Nishihara S, Ota Y 1980 Dilatation of the ductus arteriosus by prostaglandins and prostaglandin's precursors. Pediatr Res 14:1074-1077

11. Momma K, Takeuchi H 1983 Constriction of fetal ductus arteriosus by nonsteroidal anti-inflammatory drugs. Prostaglandins 26:631-641

12. Sugimoto I, Kuchiki A, Nakagawa H 1981 Stability of nifedipine polyvinylpyrrolidone coprecipitate. Chem Pharm Bull 29:1715-1723

13. Armitage P 1971 Statistical Methods in Medical Research. Blackwell Scientific Publications, Oxford, pp 217-225

14. Opie LH 1987 Calcium channel antagonists. Part 1: Fundamental properties: mechanisms, classification, sites of action. Cardiovasc Drugs Therap 1:411430

15. Nakanishi T, Jarmakani JM 1984 Developmental changes in myocardial mechanical function and subcellular organelles. Am J Physiol 246:H615H626

16. Desjardins S, Mueller RW, Cauchy MJ 1988 A pressure overload model of congestive heart failure in rats. Cardiovasc Res 22:696-702

17. Rizzo G, Arduini D, Mancuso S, Romaini C 1987 Effects of nifedipine on umbilical artery velocity waveforms in healthy human fetuses. Gynecol Obstet Invest 24:151-154

18. Coe JY, Loundes D, Coceani F, Olley PM 1986 The circulatory effects of nifedipine in the conscious newborn lamb. Pediatr Res 20:1-4

19. Harake B, Gilbert RD, Ashwal S, Power GG 1987 Nifedipine: effects on fetal and maternal hemodynamics in pregnant sheep. Am J Obstet Gynecol 157:1003-1008 